\title{
What Should We Eat for Healthy Longevity? Necessity of Tailor-Made Nutrition
}

\section{Shaw Watanabe ${ }^{1 *}$, Azusa Hirakawa ${ }^{1}$, Shoiichi Mizuno ${ }^{1}$ Shu Wakino ${ }^{2}$ and Keika Adachi ${ }^{2}$}

${ }^{1}$ Life Science Promoting Association, Japan

${ }^{2}$ Keio University, School of Medicine, Japan

*Corresponding Author: Shaw Watanabe, Life Science Promoting Association, Japan.

DOI: 10.31080/ASNH.2020.04.0657
Received: February 21, 2020

Published: February 28, 2020

(C) All rights are reserved by Shaw

Watanabe., et al.

\section{Abstract}

The relationship between food and health has long been discussed since the Greek era and ancient times in China. In the latter half of the $19^{\text {th }}$ century, the relationship between nutrient deficiency and disease began to be linked, and in the latter half of the $20^{\text {th }}$ century, excessive intake of fat and meat to cause obesity, and pandemic increase of lifestyle related diseases became a serious problem worldwide. In the $21^{\text {st }}$ century, the balance of nutrients is expected to keep healthy longevity. Although modern nutrition has an epidemiological approach, short-term studies cannot reveal a true link. We have to observe 20-30 years to know the real effects of dietary life habit.

Nutrition has changed dramatically over the past decade, such as carbohydrate restricted diet, high fat diet, egg and cholesterol, omega-3, omega- 6 fatty acid ratio, etc. What is really necessary for healthy longevity? Japanese longevity is related to the long dietary habit, especially by brown rice eating and fermented soy products. In particular, Ishizuka's way of consuming brown rice and vegetarian diet (macrobiotics) has been re-evaluated. Comprehensive approach to each person by tailor-made nutrition is necessary to invite people to do better dietary practice.

Keywords: History of Nutrition; Energy Source; Energy Expenditure; High Protein Diet; Renal Failure; Brown Rice; Medical Rice; Spiritual Life

\section{Western and oriental nutritional science}

In Japan, two independent streams of nutrition have been present. Western nutritional science was built by Tadasu Saiki (18861959). He studied physiology in the Yale University with Professor Chittenden, and after returning to Japan, he developed a concept of nutritional science, and built the Imperial Institute of Nutrition in 1912 [1]. He also made a school to educate dietitians in 1924, which is the first trial in the world. His work improved much the Japanese health status through balance of dietary intake. He organized the Bandung Conference organized by the United Union in 1937, and the participant countries expressed the necessity to make the institute of nutrition in each country.

Another way is Sagen Ishizuka (1851-1909), who was a successor of oriental medicine in Tokugawa era, but studied western medicine after Meiji revolution [1]. He issued the balance of $\mathrm{Na}-\mathrm{K}$ is important, and brown rice had the best balance. So, he recommended brown rice and green yellow vegetable diet. Saiki stressed the importance of major nutrients, and Ishizuka's theory included balance of Ying-Yang. He issued that life depends on foods, humans fit to eat crops, domestic foods support life and whole eating are principles. Both streams were independently present and I try to integrate these for eating education (Shoku-ikku) [2,3]. The health of elderly people depends on their lifestyle from young adult age. Shokuiku-act was established in 2005, and eating education has started from childhood [4].
Accumulating evidence from recent RCT and cohort studies with long observation periods call for revolutionary changes in the dietary therapy $[5,6]$. With the increase of life-style related diseases, the improvement of dietary habits and physical exercise have become more important than drug therapy $[7,8]$. To meet the challenge of an increasingly older population, proper eating education and practices becomes more important to build a healthy aging society. Insufficient nutrition in elderly people often progresses to senile diseases [9]. A comprehensive preventive method for Alzheimer's disease was implemented in Japan [10].

Energy source intake to control obesity

I would like to focus on the 4 points for healthy longevity; Energy source intake and risk of calorie restriction [11], adequate protein intake [12], benefit of brown rice [13], and importance of eating education [2].

Energy balance is needed to build good health, and individually adjusted regimens should be elaborated by using more comprehensive methods [11]. Energy source intake can be calculated by the bomb calorimeter or food composition tables, and the energy expenditure can be measured by the Douglas bag, accelerometer, human calorimeter and/or doubly labeled water method (Figure 1) $[11]$. 


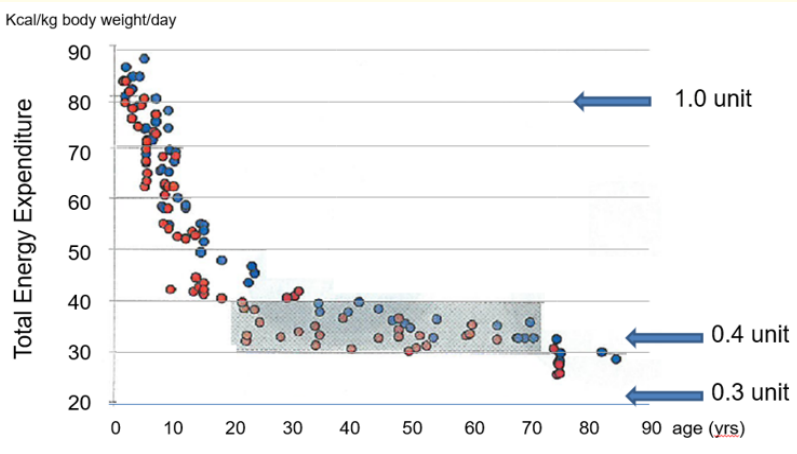

Figure 1: Total Energy Expenditure (TEE) by age group average from summary of 139 studies of healthy subjects measured by the double labeling water method. Data are obtained from healthy people at BMI 18.5-30.0 and PAL less than 2.0. TEE is 30 - $40 \mathrm{kcal} /$ kg body weight/day from age 20's to 70's years old. Data of old age are insufficient, but at least 0.3 unit ( $24 \mathrm{kcal})$ is considered to prevent frailty.

If $80 \mathrm{kcal}$ is taken as 1 unit, we found that weight $\mathrm{x} 0.4$ unit is a guide for adult age in both males and females (Figure 2) [12]. It is also applicable for pregnant women. One unit could be defined as the heat to melt $1 \mathrm{~kg}$ of ice. For example, a person weighing $60 \mathrm{~kg}$ multiplies by 0.4 needs 24 units. If you divide this into three meals in the morning, noon and evening, you will get 8 unit for each. This can be easily calculated in mind and easy to practice. Kilocalorie or joule is not easy to understand and implement to the daily eating practice is difficult for ordinary people. It is the reason why obesity people could not lose their body weight. If the people of obese or thin, they can use the ideal body weight instead of the actual body weight.

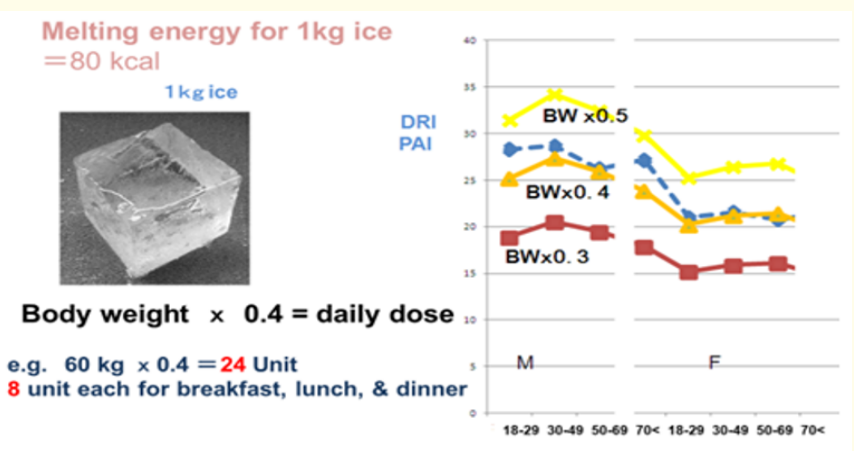

Figure 2: Comparison between unit system and the Dietary Reference Intake in Japan (blue dotted line). Body weight $\mathrm{x} 0.4$ is well fit to the DRI at Physical Activity Level 2 in both males and females.

One unit $80 \mathrm{kcal}$ system is also employed in the Japanese Food Exchange Table of the Diabetic Association [13]. One slice of bread, one egg, $30 \mathrm{~g}$ of meat, etc. are all one unit, so it is easy to remember

With this method, it is possible to memorize how many units were eaten at morning, noon and dinner. People do not eat the
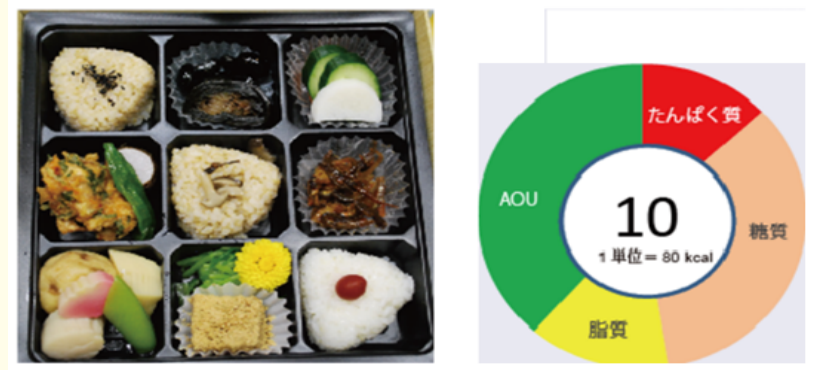

Figure 3: Healthy bento (lunch box) composed of three different rice cake and vegetable side foods.

Food icon shows that this lunch is 10 unit ( $800 \mathrm{kcal})$ and the balance of protein (red), carbohydrate (brown), fat (yellow) and antioxidant unit (green) as a surrogate marker of green yellow vegetables.

same dishes every day. It is easy to adjust eating volume between days. According to the actual survey, the variation in human energy intake is about CV0.3, so a certain target value will be closer to the target energy intake according to the central limit theorem. We have proposed a food label to show the unit of energy and composition of carbohydrate, protein, fat, and antioxidant activity as a surrogate marker of green-yellow vegetables (Figure 3). This could be labeled on food or menu. If you eat meal with four different colors, you can intake the necessary vitamins and minerals [12].

\section{High protein intake and renal function}

Nearly 330,000 hemodialysis patients are present in Japan, and new cases are 30,000 each year, in which $1 / 3$ are diabetic complication [14]. The end-stage CKD has been mostly due to diabetes or chronic glomerulonephritis, but recently age-related decrease of eGFR becomes apparent [15]. We are observing the change of eGR in the population based cohort study (Figure 4) Usually, $1 \mathrm{ml}$ of eGFR decreased by a year, when the proper amount of protein is consumed. If the protein intake increase, the decreasing rate of eGFR becomes much up to 5-10 $\mathrm{ml}$ per year. When we examined the dietary habits of them, all of them preferred eating meat. Blood urea nitrogen is a good marker of protein intake. If BUN is less than $15 \mathrm{mg} / \mathrm{dl}$, the risk of hemodialysis would be almost zero (Figure 4 right). The risk of hemodialysis until age 80 is $1 / 50$ in males and $1 / 100$ in females in our cohort. CKD is associated with the development of cardiovascular disease. If a few percent people are identified at high risk in an early stage of CKD and the implementation of low protein (brown rice) diet confirmed by the intervention, the population-based prevention could be attained [16-18].

\section{Side effects of carbon restriction}

The ratio of P:F:C should also be reevaluated, because the recent popularity of low carbon diets may lead to high-protein high-lipid regimens, resulting in renal dysfunction and/or hyperlipidemia with progressive atherosclereosis [19]. In vivo effective energy production from proteins would be half of the Atwater's coefficient, because of the diet-induced thermogenesis. More studies should be 
conducted on keto acids as energy sources in case of fasting therapy and on the influence of intestinal bacteria by changing diets [20-23].
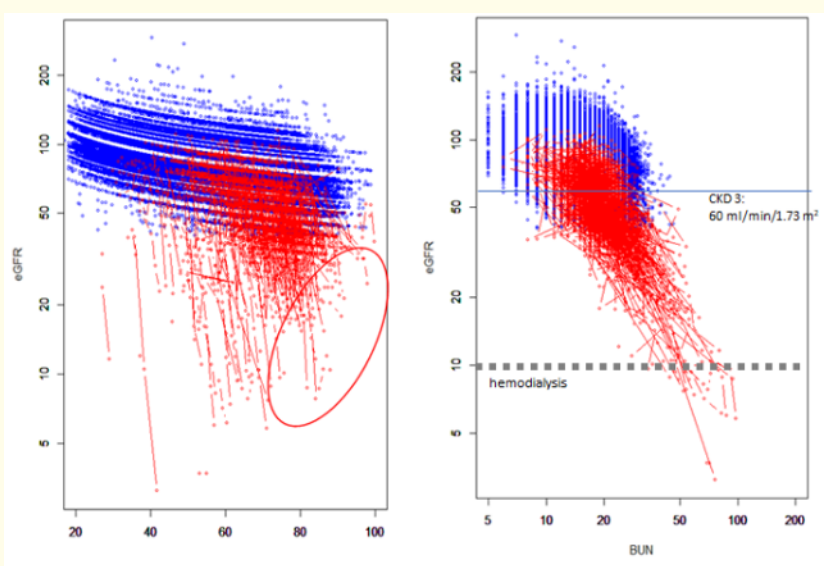

Figure 4: eGFR decrease in SAKU cohort study. High risk subgroup in aged is noteworthy (red circle). There is no risk when BUN value is less than $15 \mathrm{mg} / \mathrm{dl}$.

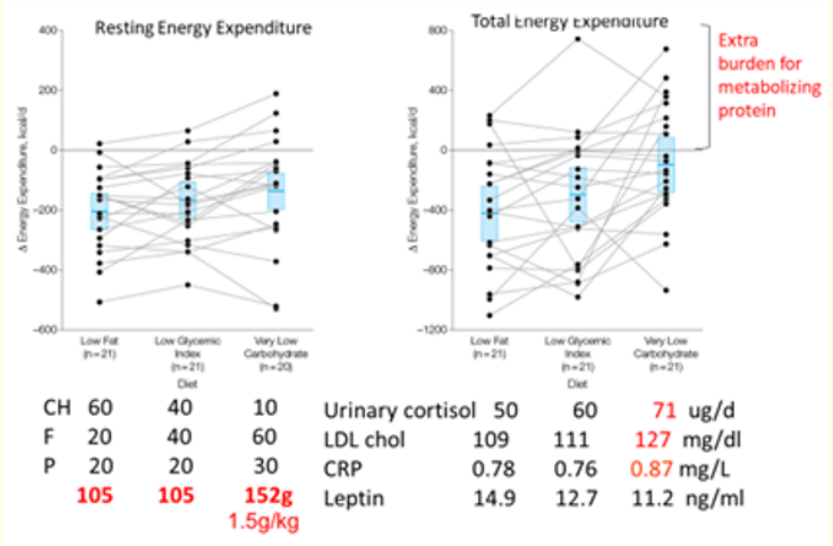

Figure 5: Effects of dietary composition on Energy Expenditure during weight-loss maintenance.

High protein group seems to give excess burden on TEE for metabolizing protein. It gives metabolic stress, which is shown by urinary cortisol and CRP. LDL cholesterol is also raised by high fat intake. Modified from JAMA 2012:307(24):2627-2634. Doi:10.1001/jama.2012.6607.

What should we eat? Or, how much could we eat? becomes the big issue according to the aging population expands on the earth. The great poet "Kenji Miyazawa" sang in his poem, "eat 4 cup of brown rice and miso soup with some vegetables" to live [24]. I long considered that it was a story of old time without enough variety of foods in the poor Tohoku area. However, after the Tohoku disaster caused by the tsunami, dietitians reported that the people in shelter suffered by a lack of meat, eggs, and protein foods. So, I wondered how about the nutritional value of old Kenji's style meal. After the measurement, I was astonished by the completeness of brown rice and miso soup meal (Figure 6).

Additional benefit of brown rice eating is the antioxidant activity and good intestinal bacteria composition of brown rice (Figure 7) [25-28].

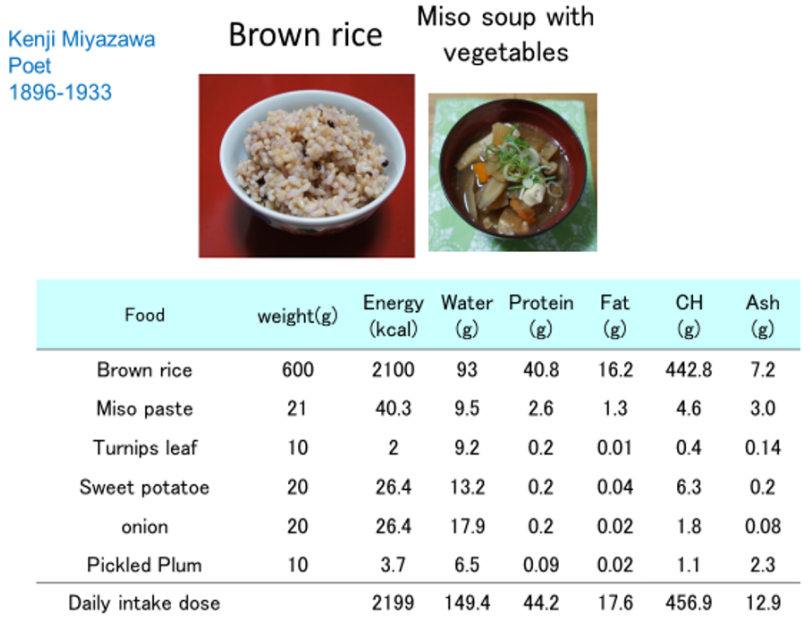

Kenji diet and DRI2010
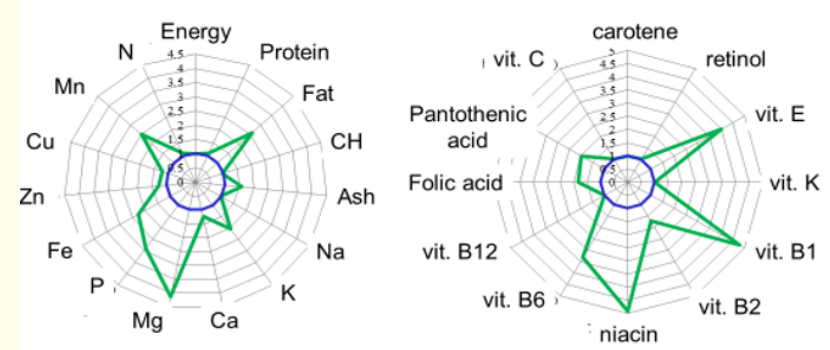

Figure 6: Nutritional aspect of Kenji's poem (upper). Comparison with DRI (central blue circle) by the Ministry of Health, Labour and Welfare and Kenji's meal (green radar chart). Several times more intake of vitamins and minerals are possible.

In addition to the ordinary nutrients, natto and fermented soy bean miso have a high antioxidative capacity among the Japanese foods [29]. Brown rice showed a good antioxidative capacity among crops, but polished rice lost its activity (Figure 7). A daily consumed dose of rice is five times more compared to other soy products, so the total activity should yield large antioxidant activity. We consider such a continuous intake should contribute to the healthy longevity of Japanese.

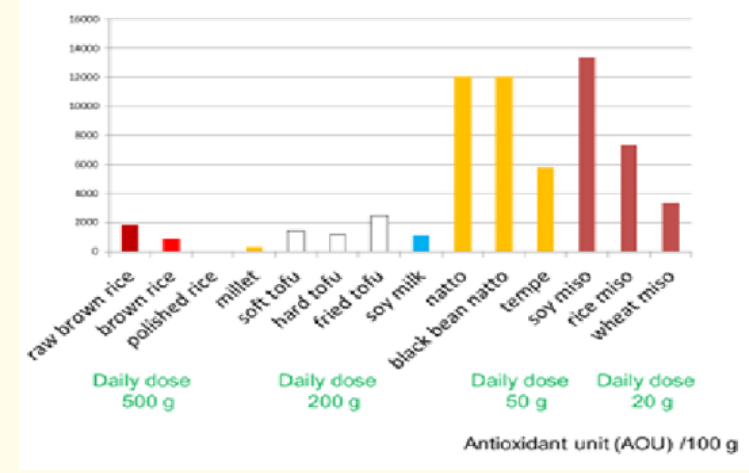

Figure 7: Antioxidant activity of brown rice and common soy foods. 
Pursuit spiritual life for healthy living

Paradigm change to the patient-centered therapy from the paternal medicine is a worldwide trend. Evidences obtained from RCT should change to build advanced epidemiology based evidence network corresponding to the recent narrative medicine. We consider holistic medicine is requested more and more by the patients, and they need the tailor-made nutrition, at least for the dietary therapy $[30,31]$.

We are proposing the new concept of preventive medicine that advanced from the integrated wisdom (Figure 8). It supports the spiritual life by three axis; food, mind, and body. Each axis has science and arts. Practical methods, such as yoga-aryurveda, acupuncture, and herbal medicine, are included beyond the ordinary western medicine $[30,32]$.

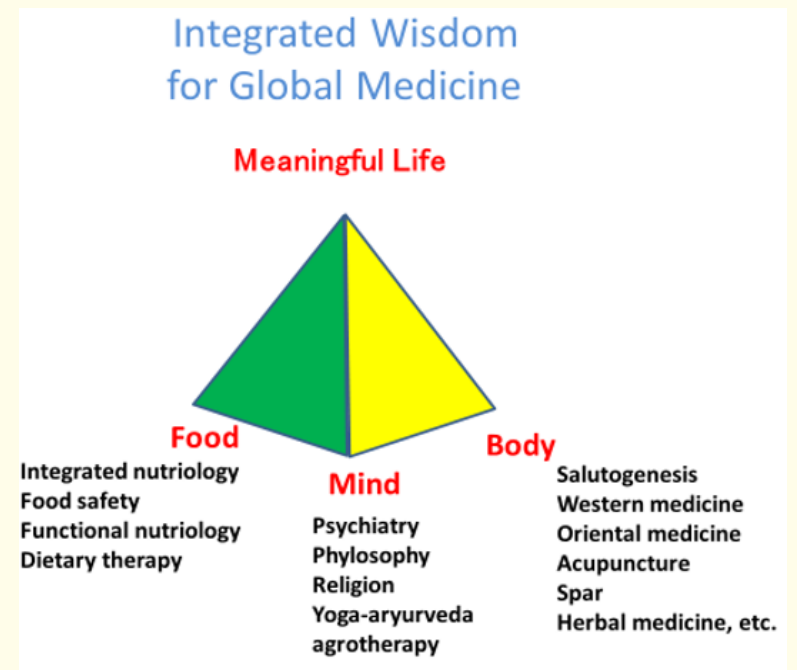

Figure 8: Tetrahedral model of the integrated practice for healthy longevity. Meaningful or spiritual purpose of living is an important component of health making.

\section{Conclusion}

What should we eat? Or, how much could we eat? becomes the big issue for individuals. Comprehensive guideline is necessary, but common sense of nutrition has changed dramatically over the past decade, such as carbohydrate restricted diet, high fat diet, egg and cholesterol, omega-3, omega- 6 fatty acid ratio, etc. From historical evidence, energy source intake is most important to keep a figure, and body weight by 0.4 unit ( 1 unit = $80 \mathrm{kcal}$ ) is a good daily estimate of intake for individuals. Protein intake is $0.8 \mathrm{~g} / \mathrm{kg} / \mathrm{day}$, and if kidney function decreases, it should be reduce to $0.4-0.6$ $\mathrm{g} / \mathrm{kg}$ protein/day. Healthy range of protein is $15-20 \%$, so hyperproteinemia is a risk of decrease of renal function. Fat would be $25-30 \%$ of total energy intake, and $\omega 3 / \omega 6$ ratio is recommended to be 1:2. Japanese longevity is related to the long dietary habit, especially by brown rice eating and fermented soy products. Traditional Ishizuka's way of consuming brown rice and vegetarian diet (macrobiotics) has been re-evaluated. Comprehensive approach to each person by tailor-made nutrition is necessary to invite people to do better dietary practice by themselves.

\section{Acknowledgement}

A part of this work is supported by the grant from the Ministry of Agriculture, Forest and Fishery.

\section{Bibliography}

1. Watanabe S. "Principles of Nutrition”. Nanko-do, Tokyo (2004).

2. Melby M and Watanabe S. "Shokuiku -Eating Education in Japan". Clinical and Functional Nutriology 2 (2006): 1-56.

3. Melissa M., et al. "Overview of nutrition reference and dietary recommendations in Japan: application to nutrition policy in Asian countries". Asia Pacific Journal of Clinical Nutrition 17 (2008): 394-398.

4. Watanabe S., et al. "Food as medicine: The new concept of "medical rice". Advances in Food Technology and Nutritional Sciences 2 (2016): 38-50.

5. Watanabe S. "Current controversies around carbohydrate restriction”. Diabetes Research Open Journal 1 (2015): e7-e10.

6. Ito H., et al. "Drastic changes in nutrition". Clinical and Functional Nutriology 11.1 (2019): 10-18.

7. Watanabe S. "Population-based strategy for preventing diabetes and its complications". Diabetes Research Open Journal 4.1 (2018): e1-e4.

8. Watanabe S. "Waist circumference in the diagnosis of metabolic syndrome: Debate and solution". Annals of Nutrition and Food Science 2.3 (2018): 1022.

9. Watanabe S., et al. "Longevity and elderly care: lessons from Japan”. Global Health Journal 2.4 (2018): 5-10.

10. Bredesen D. “The End of Alzheimer's. The first program to prevent and reverse". Mercola.

11. Hirakawa A., et al. "Comprehensive food labeling for obesity control". Advances in Obesity, Weight Management and Control 4.3 (2016) 00088.

12. Watanabe S. "Simple Food Icon for the tailor-made nutrition". Clinical and Functional Nutriology 1.1 (2009): 51-53.

13. Kagawa Y. "Food composition table of 80 kcal. 7th version". Joshi-Eiyo-Shuppan, Tokyo (2016).

14. Current status of renal diseases. https://www.mhlw. go.jp/file/05-Shingikai-10901000-Kenkoukyoku-Soumuka/0000188090.pdf

15. https://www.jstage.jst.go.jp/article/jpnjnephrol1959/46/

16. Watanabe S. "Low-protein diet for the prevention of renal failure". Proceedings of the Japan Academy, Ser. B 93 (2017): 1-10. 
17. Levy AS., et al. "Chronic kidney disease as a global public health problem: approaches and initiatives--A position statement form Kidney Disease Improving Global Outcomes". Kidney International 200772 (2007): 247-259.

18. Watanabe S. "Low protein brown rice for preventing progression of CKD and DKD to end stage renal failure". Diabetes Research Open Journal 4.1 (2018): e5-e7.

19. Watanabe S. "Effects of low carbohydrate diet for obesity control: meta-analysis". Clinical and Functional Nutriology 6 (2014): 300-303.

20. Watanabe S. "Rice function for disease prevention and establishment of medical rice association". Diabetes Research Open Journal 5.1 (2019): e1-e3.

21. Utada I., et al. "Wellness fasting for healthy longevity". Advances in Food Technology and Nutritional Sciences 2.3 (2016): 103-109.

22. Watanabe S., et al. "Basic ketone engine and booster glucose engine for energy production". Diabetes Research Open Journal 2 (2016): 14-23.

23. Watanabe S., et al. "Wellness Fasting and Intestinal Microbiota in Chronomedicine". Acta Scientific Nutritional Health 3.1 (2019): 35-43.

24. https://bungostraydogs.fandom.com/wiki/Kenji_Miyazawa

25. Watanabe S., et al. "Effects of Brown Rice on Obesity: GENKI Study I (Cross Sectional Epidemiological Study)". Journal of Obesity and Chronic Diseases 2 (2018): 12-19.

26. Hirakawa A., et al. "The Nested Study on the Intestinal Microbiota in Genki Study with Special Reference to the Effect of Brown Rice Eating". Journal of Obesity and Chronic Diseases 3 (2019): 1-13.

27. Shimabukuro M., et al. "Effects of the brown rice diet on visceral obesity and endothelial function: the BRAVO study". British Journal of Nutrition 111 (2014): 310-320.

28. Kozuka C., et al. "Impact of brown rice-specific $\gamma$-oryzanol on epigenetic modulation of dopamine D2 receptors in brain striatum in hig-fat-diet-induced obesity in mice". Diabetologic 60 (2017): 1502-1511.

29. Watanabe S and Uehara M. "Health Effects and Safety of Soy and Isoflavones. Chapter 22". In The Role of Functional Food Security. Elsevier (2019): 379-394.

30. Singh RB., et al. "Diet and Lifestyle Guidelines and Desirable Levels of Risk Factors and Protective Factors for Prevention of Dementia: A Scientific Statement from Joint Symposium of JAAS and Asia Pacific Clinical Nutrition Society". Biomedical Journal of Scientific and Technical Research (2019).
31. Takada A and Shimizu F. "Correlation of various foods intakes and plasma levels of omega fatty acids in healthy Japanese old men". Journal of Food and Nutrition Sciences 10 (2019): 578587.

32. Watanabe S. "Rice function for disease prevention and establishment of medical rice association". Diabetes Research Open Journal 5.1 (2019): e1-e3.

\section{Assets from publication with us}

- Prompt Acknowledgement after receiving the article

- Thorough Double blinded peer review

- Rapid Publication

- Issue of Publication Certificate

- High visibility of your Published work

Website: https://www.actascientific.com/

Submit Article: https://www.actascientific.com/submission.php Email us: editor@actascientific.com

Contact us: +919182824667 